\title{
Open Video Repositories for College Instruction: A Guide to the Social Sciences
}

\author{
Michael V. Miller \\ University of Texas at San Antonio \\ A. S. CohenMiller \\ Nazarbayev University, Kazakhstan
}

\begin{abstract}
Key features of open video repositories (OVRs) are outlined, followed by brief descriptions of specific websites relevant to the social sciences. Although most were created by instructors over the past 10 years to facilitate teaching and learning, significant variation in kind, quality, and number per discipline were discovered. Economics and psychology have the most extensive sets of repositories, while political science has the least development. Among original-content websites, economics has the strongest collection in terms of production values, given substantial support from wealthy donors to advance political and economic agendas. Economics also provides virtually all edited-content OVRs. Sociology stands out in having the most developed website in which found video is applied to teaching and learning. Numerous multidisciplinary sites of quality have also emerged in recent years.
\end{abstract}

Keywords: video, open, online, YouTube, social sciences, college teaching

Miller, M.V. \& CohenMiller, A.S. (2019). Open video repositories for college instruction: A guide to the social sciences. Online Learning, 23(2), 40-66. doi:10.24059/olj.v23i2.1492

\section{Author Contact}

Michael V. Miller can be reached at michael.miller@utsa.edu, and A. S. CohenMiller can be reached at anna.cohenmiller@nu.edu.kz.

\section{Open Video Repositories for College Instruction: A Guide to the Social Sciences}

The current moment is unique for teaching. ... Innovations in information technologies and the massive distribution of online content have called forth video to join textbook and lecture as a regular component of course instruction (Andrist, Chepp, Dean, \& Miller, 2014, p. 203).

Websites that direct free online videos to instructors and students, what we call open video repositories (OVRs), have proliferated over the past decade. ${ }^{1}$ OVRs have the potential to significantly augment course content by aggregating video relevant to teaching and learning, thus

\footnotetext{
${ }^{1}$ We hesitate to use the phrase open education video repositories, as it may suggest that we are referring to content that qualify under common definitions of open education resources (e.g., resources that "reside in the public domain or have been released under an open license that permits no-cost access, use, adaptation and redistribution by others with no or limited restrictions" (UNESCO, 2018). We prefer to use the phrase open video repositories to denote that we are simply centering on websites that offer free videos that can be used in courses.
} 
permitting instructors to use such media without cost and without having to expend effort searching the Internet. Quality sites, moreover, add further value by offering practical assistance on how videos can be employed in instruction. However, OVRs have yet to be systematically addressed in the literature with regard to either the availability of free teaching resources relevant to higher education (e.g., Coiffe, 2014; Palmer \& Schueths, 2014) or the use of video in college instruction (e.g., Alpert, 2016; Andrist, Chepp, Dean, \& Miller, 2014; Berk, 2010; Daniels, 2012; Kaufman, 2007; Miller, 2011; Sherer \& Shea, 2011; Snelson, 2011; Streeter, 2011).

Innumerable websites contain videos that could be used for teaching and learning purposes, but we address here only those that have freely accessible content relevant to college-level courses within the social sciences. Paid-subscription sites (e.g., Films on Demand, SAGE Video) are therefore excluded, as are publishing platforms for developers, such as YouTube, and sites featuring video appropriate only to precollege students. Not examined either are websites that include videos potentially relevant for college courses but largely directed to general audiences, such as newspapers (e.g., The New York Times), magazines (e.g., The Atlantic), television program (e.g., National Geographic) collections, intelligent interview sites (e.g., Big Think), and general documentary sites comprised of either original (e.g., Vice) or found (e.g., Snagfilms) content. Likewise not considered are speech or lecture websites (e.g., Jordan B. Peterson's YouTube channel), online college courses (e.g., Academic Earth), tutorial sites (e.g., Khan Academy), massive open online course (MOOC) sites (e.g., Coursera), and those collections with significant educational value but with subject matter too narrow to represent a discipline or major subfield within a discipline.

OVRs are introduced here as a growing and valuable free teaching resource. We describe their key features and variable nature across the social sciences and, in doing so, recognize specific OVRs for the creativity and effort expended by their developers. By pointing instructors to free curated media appropriate to their interests, we hope to motivate further investigation of such resources for employment in their teaching. Moreover, OVRs are especially relevant at present in light of the prominence of online learning. OVR content can be easily integrated into Internet courses to supplement text-based materials. Finally, we encourage instructors to not only use OVRs but also make them - particularly in disciplines where they are underdeveloped. Given that instructors are commonly walled within disciplinary silos, we encourage prospective curators to become acquainted with the significant range of OVRs found across the social sciences to facilitate that end.

\section{Methods and Descriptive Framework}

In performing this review, we first identified relevant websites, and then distilled general features. Sites were located through search and discovery engines, video aggregators, Twitter, and posts in Dan Colman's excellent educational multimedia website Open Culture (e.g., Marshall, 2014). We searched MERLOT, the largest online collection of peer-reviewed free higher education teaching resources, and likewise examined articles available about specific sites (e.g., Caldeira \& Ferrante, 2012; Macfarlane, Harrison, \& Turin, 2005). We also employed the Internet Archive's Wayback Machine to examine websites no longer online, although those that are archived do not exactly mirror their former live versions (Brugger, 2009). Finally, we contacted many OVR developers by email to resolve questions we had about their websites. 
In describing OVRs, we consider website background, video characteristics, and website features. Relevant to background, we provide a hypertext link to the repository and identify the developer(s). We tried to determine motives for site creation and source of financial support. We also specify date of site initiation and indicate whether the site continues to upload new video materials. For all but recently initiated sites, the last full year (2018) was the benchmark in terms of persistence of activity. The last year in which content was added is specified for developers who did not augment content during 2018. We should also note that all hypertext links appearing in the article were live as of January $15,2019 .^{2}$

Video characteristics relate to the quantity of videos at the site $(N)$, type of video content provided, and a link to a sample video from the repository. Identifying the source of the content is also important, given the distinction between original videos (those created by developers themselves to present a didactic message), edited videos (those edited by developers from DVDs or existing online videos, typically copied from popular television series or movies), and found videos (those produced by others that are already available on the Internet, either linked directly to source origin or embedded within the OVR). These preparation forms stand in contrast to referral, the dominant way copyrighted film content was treated on the Web before the rise of streaming technology and OVRs. ${ }^{3}$

We should note that types of content source are treated differently under copyright law. Although website developers who make their videos are not restricted, those working with found or edited content should be mindful of legal constraints if such content is used without permission of owner. Found video can be legitimately distributed by OVRs without permission if made available to users via hypertext link to source. However, under fair use, legitimate employment of edited copyrighted content comes with standards related to purpose, length, and other considerations (see Jaszi \& Aufderheide, 2008).

Pairing clips with instructional applications is important for using video in the classroom, especially for sites employing found or edited content. Whereas original-content sites are typically populated with explainer videos, in which teaching points are explicitly incorporated, such points generally do not reside within found and edited media. That is, while a scene from a TV show or movie illustrates a concept in the developer's mind, it may not be apparent to others. Commenting on the value of using found and edited video in sociology, Andrist et al. (2014) write, "Our own experience suggests that students generally find those not explicitly created for teaching sociology more compelling. In a similar way that archeologists can better engage students by using real artifacts discovered in situ, video taken from the 'real world' can be used by sociologists to imaginatively demonstrate sociological ideas. Yet, without their content being framed ... such videos are likely to remain untapped" (p. 203). Consequently, we address website characteristics in terms of the extent to which teaching and learning suggestions are applied to video content either within the clip itself or through text commentary. Also we determine whether OVRs help users locate videos within the site, facilitate user sharing with followers, and encourage user interaction or user participation in site development. Recognition of OVRs in the broader literature, including awards received, is likewise noted.

\footnotetext{
${ }^{2}$ Should a link subsequently break, readers may copy and paste its URL to the Wayback Machine (archive.org/web/) search engine to derive a facsimile of the inactive website.

${ }^{3}$ With referral, video is not available for play online. Rather, sources of clips, such as a given DVD or certain locations on a DVD, are specified, and users then must procure resources on their own (for current examples of referral, see Al-Bahrani \& Patel, 2015; Ghent, Mateer, \& Stone, 2011). Another option, offering downloadable clips on the website, is no longer common, given the superiority of streaming.
} 


\section{OVRs by Discipline}

OVRs were categorized in terms of primary social science disciplines (anthropology, economics, history, political science, psychology, and sociology). Sites having major bodies of content relevant to two or more social sciences were deemed multidiscipline OVRs. In this section, we address disciplines sequentially in terms of the number and size of OVRs offered in each and then review those that are multidisciplinary in nature.

Economics. Although economics clearly stands out by having the greatest quantity of instructionally relevant teaching OVRs, we found the discipline to have two substantially different types. The first consists of those that are largely applied in nature that center on the influence of public policy on the economy. They tend to be sponsored by conservative organizations espousing free-market arguments and are professionally produced. The second set is more politically neutral, primarily focused on standard economic principles and concepts, and are exclusively developed by economics instructors.

In our opinion, the most creative OVR videos to emerge in the past decade are those in EconStories (econstories.tv/, 2010-present, $N>35$ ), initiated by John Papola (former MTV producer and founder of Emergent Order) and Russell Roberts (former George Mason University professor, now fellow at Stanford's Hoover Institute). Offering original dramatic comedy, the OVR's first videos, Fear the Boom and Bust (Papola \& Roberts, 2010) and its sequel Fight of the Century (Papola \& Roberts, 2011), are heated rap battles between actors playing John Maynard Keynes and Friedrich Hayek that center on Austrian school criticisms of mainstream liberal economic policy. Fear the Boom and Bust won the 2010 Sammies, and the two videos together have received over 10 million hits on their YouTube companion site. In 2014, Papola added EconPop, a series of popular movie remixes starring comedian Andrew Heaton that illustrate the harmful effects of government intrusion (see Dallas Buyers Club, Papola, 2014). And in 2017, the site started distributing Share Wars, a remix series, created by Papola's Emergent Order in collaboration with Artists 4 America, parodying attempts to regulate the new sharing economy using satirical voice-overs across edited scenes from the Star Wars franchise. His interest in warning youth about the dangers of government overreach is again evident in the comedic web TV series Love Gov (independent.org/lovegov/, 2015 and 2018), which has received several awards from libertarian film festivals ("Love Gov in the News," 2017). Papola's work has been funded by various conservative organizations, including the Searle Freedom Trust and the Robert and Marie Hansen Foundation.

The standard approach to teaching libertarianism nevertheless has been a bit more mundane. The first coherent set of videos and ancillaries were offered online through television news personality John Stossel. Stossel has long criticized dominant liberal policies and practices through a libertarian lens in his work at $\mathrm{ABC}$ and later at Fox News. The initial version of his teaching package began almost 20 years ago as a for-purchase set of DVDs and learning applications aimed at high school and college instructors based mostly on segments from the ABC series 20/20. During his Fox tenure, he consistently added original and found videos to its present incarnation, Stossel in the Classroom (stosselintheclassroom.org/), where he typically transcends purely economic concerns in addressing what he sees as irrational impediments imposed by government (e.g., "Eye Test Innovators," Stossel, 2017a). Videos, which can also be procured at no cost in DVD form, are accompanied by teaching guides, discussion questions, and external resources. The OVR is funded by The Center for Independent Thought, initiated by noted libertarian movement leaders Howard and Andrea Rich (Zaitchik, 2013). New content is now 
available as well on Stossel on Reason, a weekly column started in 2017 on Reason.com that he says allows him to address important issues free of corporate television constraints (see "Launch of Stossel TV," Stossel, 2017b).

Several other OVRs provide original content supported by market-based foundations that could be used in either high school or intro-level university courses. PolicyEd (policyed.org/series, 2016-present), sponsored by Stanford's Hoover Institute, offers a set of 14 modules with multiple videos and discussion leads, exam questions, and user comments. Two of the best in our opinion are contributions from the aforementioned Russell Roberts, which range from the empirical ("The Numbers Game," 2017b, to the poetic "It's a Wonderful Loaf," 2017a). The Foundation for Economic Education (FEE; fee.org/), which started in 1946, has long worked through high schools and colleges to influence economic reasoning and loyalties but only recently shifted from relying on print to digital materials (see "A new FEE for the 21st Century," FEE, 2017). New collections there dispense free-market thought through such topics as individual liberty, common sense, and female entrepreneurs. Students may find the Out of Frame series to be especially appealing, as it employs remixed pop-culture media to address various moral issues (e.g., "The Anti-Authoritarian Politics of Harry Potter," FEE, 2018). The latest film with full ancillaries from Thor Halvorssen's Moving Picture Institute (thempi.org/, 2006-present) is 2081, a dystopian drama about government efforts to erase inequalities of condition based on a popular Kurt Vonnegut book. Along with a number of other dramatic films, the MPI also offers the animated series FI\$H: How an Economy Grows, directed to younger students.

However, the most extensive conservative agenda centered specifically on college audiences is being pursued by Learn Liberty (learnliberty.org/, 2011-present) at George Mason University (GMU). The website is sponsored by the university's Institute for Humane Studies (HIS), an entity in turn largely supported through contributions from antiregulation industrialist Charles Koch (Barakat, 2016; SourceWatch, 2016; Young, 2014; for a larger analysis of the role of Koch money at GMU and other universities, see Mayer, 2016). Learn Liberty is a key part of Koch's vision to not only bring student masses to his way of thinking but also create a "talent pipeline" through which affiliated students ultimately become academicians and economic and political leaders who will support conservative activism (Gibson, 2017; Kotch, 2017). The website provides over 300 original-content videos accompanied by summaries, transcripts, and references. Many combine narration by economics professors from GMU and elsewhere with slick graphics and animations (e.g., "Economics: Is Raising Minimum Wage a Bad Idea?" Learn Liberty, 2016). Although primarily centered on economics, the site also tackles a range of social and political issues - often by employing themes drawn from popular movies (e.g., "Is Katniss a Modern-Day Spartacus?" Learn Liberty, 2013) and edgy television series (see "Frank Underwood's Top Three Lessons for the Voting Public: House of Cards Review," Learn Liberty, 2014a) —as well as focusing on timely social controversies (e.g., "I Can't Breathe: How to Reduce Police Brutality," Learn Liberty, 2015a). Each video is accompanied by an interpretive essay, linked readings, and downloadable MP3 file. In addition to using popular culture, Learn Liberty has tried to generate further interest through student video responses to intriguing questions (see its "\#keepaskingwhy" feature, e.g., "Should You Be Allowed to Sell Your Kidneys?" Learn Liberty, 2015b) and an "On Demand Program of the Week" consisting of videos coupled with related learning resources on provocative themes (e.g., "Sexonomics: The Economics of Love and Dating," Learn Liberty, 2014b). Finally, the site offers opportunities for deeper student engagement with such libertarian ideals through career guides, summer seminars, internships, and jobs. 
In contrast to original-content conservative sites, we found little in the way of applied OVRs offering ideological alternatives. We the Economy (wetheeconomy.com/, 2014-2015), produced by the late Paul G. Allen (liberal activist and co-founder of Microsoft) and Morgan Spurlock (documentary producer and cofounder of Cinelan), consists of 23 short documentaries, musicals, and cartoons. Created by filmmakers at the top of their craft (e.g., Ramin Bahrani and Albert Hughes), videos employ professional actors, dancers, and comedians to address basic connections between the economy, government, globalization, and inequality. Allen and Spurlock state that their intent is "to demystify a complicated topic while empowering the public to take control of their own economic futures" (2014a). Videos are accompanied by synopses, director notes, and comprehension questions (e.g., "Lemonade War," Bahrani, 2014), and downloadable resources are available as well (see Allen \& Spurlock, 2014b). The OVR won the 2015 Webby for the Best News \& Politics Series.

Inequality Media (inequalitymedia.org/, 2014-present, $N>70$ ) also presents a philosophically progressive alternative but is narrower in scope than We the Economy. Nevertheless, this collection challenges conservative assumptions about inequality and also has relevance for political science and sociology courses. Here, Robert Reich, UC Berkeley economist and former Secretary of Labor, along with filmmaker, Jacob Kornbluth, have created video shorts that identify problems associated with economic maldistribution, criticize attempts to heighten inequalities, and suggest policies to generate greater equality (e.g., "The Failure of Trickle Down Economics," Reich, 2017).

In terms of OVRs directed to concepts and principles, we should first note the work of Jacob Clifford, a high school teacher from Escondido, California. While the foregoing OVRs generally incorporate highly polished media, Clifford has developed extensive content covering basic economics through talking-head, image-illustrated clips at ACDC Leadership (youtube.com/user/ACDCLeadership, 2007-present, $N>400$ ). (Teaching ancillaries are available behind a paywall.) Aimed at AP students, Clifford's work transcends other tutorial sites by blending popular culture with economics through EconMovies, an edited-video series identifying key disciplinary concepts illustrated in blockbuster movies (see "Capitalism and The Hunger Games," Clifford, 2015), as well as through clips covering contemporary controversies (e.g., "The Economics of Trump," Clifford, 2017). Several years ago, Clifford and Marketplace reporter Adrienne Hill joined John and Hank Green's YouTube megaseries to produce Crash Course Economics, integrating new clips with earlier tutorial media.

The largest collection of original videos centering on academic economics is Marginal Revolution University (mruniversity.com/, 2012-present) sponsored by the Mercatus Center, a market-oriented think tank on the campus of George Mason University. MRU was developed by GMU professors Alex Tabarrock and Tyler Cowen, current center director. The site includes free online courses related to such areas as the history of economic thought, macroeconomics, and microeconomics, employing over 800 original videos created to convey course content. We consider the site to be an important OVR, given the breadth and quality of videos, and the fact that its developers strongly encourage instructors located elsewhere to freely use their videos, teaching applications, and related resources. Instructors who want to start with a more a limited set of teaching videos covering basic economic concepts should consult the Economic Lowdown Video Series (2012-2018) produced by the Federal Reserve of St. Louis.

College instructors deserve special recognition, especially for their work in creating lowbudget OVRs on their own. In our opinion, the strongest advocate for using video in the economics 
classroom is Dirk Mateer, lecturer at the University of Arizona. His website, Econ 1-0-What? (dirkmateer.com/, 2011-present, $N>400$ ), organized into teaching ideas and media relevant to key concepts, provides clips from his lectures and found popular media (see "Gangs of New York," Mateer, n.d.). Mateer also has published significant scholarship on media integration (e.g., Ferrarini \& Mateer, 2014; Mateer, O’Roark, \& Holder, 2016; Mateer \& Stephenson, 2011), contributed to a useful website on that topic (see Mateer, Ghent, Porter, \& Purdom, 2014), and most recently, collaborated on several edited-content OVRs (see below).

The involvement of professors in independent site development is clearly evident in those OVRs employing scenes curated from popular television comedies to illustrate discipline concepts. Linda Ghent (Eastern Illinois University), Alan Grant (Baker University), and George Lesica (software engineer) started this genre with The Economics of Seinfeld (yadayadayadaecon.com/, 2010), which provides over 70 clips from the Seinfeld series, organized by 120 concepts, ranging from "absolute advantage" to "zero-sum game." Each clip has a brief summary and links to a glossary (see Ghent, Grant, \& Lesica, 2010). Similarly, The Economics of The Office (economicsoftheoffice.com/, 2013) developed by Kansas State University professor Dan Kuester, graduate student Chris Youderian, and Dirk Mateer, provides 30 scenes from The Office, with brief synopses and applications (e.g., "Write That Down," Kuester \& Youderian, 2013). Bazinganomics (bazinganomics.com/, 2015-present, $N>85$ ), created by James Tierney (Penn State), Wayne Geerling (University of Arizona), Jadrian Wooten (Penn State), Dirk Mateer, and Ben Smith (University of Nebraska, Omaha), also employs clips from a popular comedy series indexed by key concepts, in this case The Big Bang Theory. However, it went beyond other edited-content sites at the time in offering lesson plans for concepts undergraduates often find troubling (e.g., "Causation vs. Correlation," Tierney, Geerling, Wooten, Mateer, \& Smith, n.d.). Three additional edited-content OVRs using television programs have recently gone online: The Economics of Shark Tank (econshark.com/, 2017-present) by Charity-Joy Acchiardo (University of Arizona), Abdullah Al-Bahrani (Northern Kentucky University), Darshak Patel (University of Kentucky), and Brandon Sheridan (Elon University); Economics of Parks and Recreation (economicsofparksandrec.com/ 2017-present) developed by Jadrian Wooten (Penn State); and Economics of Modern Family (modernfamilyecon.com/, 2018-present) developed by Jadrian Wooten, Kalina Staub (University of Toronto Mississauga), and Susan Reilly (Florida State College). Both of the latter appear unique to edited-content OVRs by encouraging clip and teaching application suggestions from instructors and students.

Although economists have long-discussed the relevance of employing feature-length films as a classroom teaching medium (e.g., Leet \& Houser, 2002), we could find only three collections built from specific movies, movie series, or movie genres. Broadway Economics (broadwayeconomics.com/, 2015-present, $N>50$ ), developed by Matthew S. Rousu (Susquehanna University), offers a series of clips edited from various musical theater videos with extensive teaching ancillaries; University of Chicago economist Steven D. Leavitt and writer Stephen Dubner created a YouTube playlist of 29 clips from their 2010 feature film, Freakonomics; and as noted, John Papola created Share Wars.

Two found-video OVRs by instructors have also recently emerged. Economics Media Library (videoecon.wordpress.com, 2017-present) created by Jadrian Wooten has already amassed a large set of clips from movies, television programs, news stories, and commercials, augmented with brief summaries and links to related materials (e.g., "Daily Show: Ugly People Discrimination," Wooten, 2017). And Mark Melichar (Tennessee Tech University), through 
EconGoneCountry (econgonecountry.com, 2017-present), is working to establish that economics can be well-illustrated through country music lyrics. Each entry links to a music video and discusses at length concepts raised in it (see "Red, White, Pink Slip Blues," Melichar, 2017).

Finally, student involvement in creating music videos is being actively encouraged by Abdulla Al-Baharani of Northern Kentucky University and Kim Holder of the University of West Georgia. Al-Baharani created Econ Beats as a model for instructors interested in incorporating such media into course assignments (for an excellent example, see Al-Baharani, Libis, Drabick, \& Gibson, 2017), whereas Holder developed and directs an annual nationwide contest, Rockonomix, which has stimulated significant student engagement (see Holder, 2015, for an overview of the project).

Psychology. Among original-content psychology OVRs, four sites that are clearly different stand out: The Psych Files, goCognitive, BrainCraft, and Psych2Go. The Psych Files (thepsychfiles.com/, 2007-present), produced by Marist University instructor Michael Britt, is centered on audio podcasts (e.g., Britt, 2017) but also includes brief videos on diverse psychology topics. Most have summaries, as well as links to related content (Britt's YouTube channel The Psych Files conveniently aggregates over a hundred videos). Although geared to helping students learn psychology content, most are without an obvious lecture tone. Rather, Britt typically uses a humorous soft sell to convey core concepts (e.g., "If Freud Worked Tech Support," Britt, 2014). Supported through ads for tech products he has tested (personal communication with Britt, November 27, 2017), his teaching with media has received popular recognition (e.g., Lee, 2016) and various awards (including MERLOT's 2014 Classic Award).

The second large original-content site, goCognitive (gocognitive.net/, 2008-present), includes almost 200 clips from interviews with researchers about neuroscience theory, methods, and findings. Curated by University of Idaho psychology professor Steffen Werner, the site provides summaries for each clip (see "Can Synesthesia be Acquired," Werner, n.d.-a) and offers interactive learning demonstrations to illustrate key concepts (see "Monsters and Globes Problems," Werner, n.d.-b). The OVR also encourages student involvement in site development and offers National Science Foundation grants of $\$ 1,100$ to conduct interviews. The site has been well funded by the NSF and the Idaho State Board of Education.

The third original-content website of significance is BrainCraft (pbs.org/show/braincraft/, 2013-present, $N>100$ ), consisting largely of stop-motion, paper-animation videos covering intriguing yet practical questions about human behavior addressed through psychological and neuroscience research (e.g., "The Bizarre Ways Your Name Affects Your Behavior," Hill, 2016). Created and narrated by Vanessa Hill, an Australian science media specialist, the collection has been produced by PBS Digital Studios since 2014 and has received numerous positive reviews (e.g., Lanning, 2014; Weisberger, 2016). Her YouTube channel currently has almost 400,000 subscribers.

The fourth original-content OVR warranting special attention is Psych2Go (psych2go.net/, 2014-present, $N>200$ ), a site created by Tai Khuong, who was at the time of inception a University of British Columbia psychology major wanting to make the discipline more intellectually accessible to undergraduates. Psych2Go videos address key concepts, new research findings, interviews with psychologists, and, increasingly, self-help questions. The website also sells a quarterly magazine with each issue focused on a common theme. Unique among socialscience sites in the sense of being student-operated, Psych2Go relies on user contributions for 
content, actively recruiting from a membership of about 4,000 to write articles and create videos (see "10 Signs an Introvert Likes You," Psych2Go, 2017). Participation in the process also entails mentoring from Khuong and staff editors (personal communication, Khuong, July 6, 2017).

Several smaller original-content OVRs suggest promise, as well. On the site Be a People Expert (2015-present, $N>60$ ), Andrew Luttrell, an assistant professor at Ball State University, includes talking-head clips on various social psychology concepts and questions. Each video at his YouTube site comes with a rich discussion and suggestions for further reading on his blog (e.g., "A Crash Course on Cognitive Dissonance," Luttrell, 2016). Bo Bennett's Socially Psyched (2016) website includes more than 15 talking-head videos with learning applications centered thus far on classic studies in the discipline (see his treatment of compliance tactics in "Xerox Mindfulness Experiment," Bennett, 2016b) and useful teaching instructions about designing curation exercises for students (see Bennett, 2016a). Instructors may also find value in original-content sites too narrow to serve as discipline OVRs: for example, Pop Psych! (2015), a small collection of entertaining psychiatric diagnoses of pop-fiction icons from Wisecrack, would be relevant to any treatment of abnormal psychology. Although teaching applications are not provided, each cartoon injects clinical concepts relevant to the character. Finally, Psyfile (2012-2013, $N=7)$, despite its small number of videos and brief duration of output, should also be noted because it is Brady Haran's only attempt to build a social-science collection. Haran has had phenomenal success in creating a bundle of science, math, and humanities OVRs through interviews with UK professors (e.g., Periodic Videos).

Three other original-content sites suggest the utility of using research findings to inform self-help videos. Bite Size Psych $(2015-2017, N=37)$ offers a collection of short animations dealing with psychology-related conundrums and misconceptions (see "Debunking the 4 Most Dangerous Self-Help Myths,” Bite Size Psych, 2015). The unidentified developer often provides interesting learning applications in the comments section in responses to users. However, The Science of Us (2015-2017, $N=27)$, distributed by New York Magazine, is a bit more problematic. Its collection of animated shorts commonly seeks to explain self-help research in lay terms, although often without providing the identity of highlighted studies (e.g., "Is Casual Sex Unhealthy?" New York Magazine, 2016). Finally, as a spinoff of the popular Green brothers' SciShow and Crash Course Psychology, Hank Green recently started SciShow Psych (2017present, $N>190$ ). This OVR employs empirical research to address intriguing questions about the brain and human behavior (e.g., “Are Violent Video Games Bad for You?” Green, 2017).

Found-content videos are available at three OVRs. Personality Pedagogy (2006-2014), developed by Arcadia University instructor Marianne Miserandino, was the first psychology site to appear online. Funded by the Association of Psychological Science, it provides video links and other teaching resources of general interest to the discipline. PsychoTube (2008-present), developed by an anonymous Turkish psychologist, mainly posts found video from YouTube with video transcripts or Wikipedia commentary (e.g., "How Human Brains Compare to Other Animals," PsychoTube, n.d.). Clips for Class (2009-present), maintained by textbook publisher Cengage, also offers a large number of clips on a range of topics organized by subfield. Brief summaries and questions to ponder provide learning applications (e.g., "Dealing with the Office Bully," Clips for Class, 2016).

Finally, psychology has one edited-content OVR. Inspired by The Economics of Seinfeld, The Psychology of Seinfeld (2012-2013, $N=32)$ includes clips edited from the television series, 
along with summaries and interpretations organized by tags (e.g., "Morality According to Kohlberg," Psynfeld, 2012). The developer of this site chooses to remain anonymous.

History. History has far less OVR presence than economics or psychology. The largest collection of original-content video, HipHughes History (hiphugheshistory.weebly.com/, 2008present), produced by Keith Hughes, former Buffalo, New York, high school history teacher, includes more than 300 rapidly-paced, talking-head, animated lectures (10-20 minutes in length) on such diverse topics as civilizations and presidential elections (see Hughes, 2012-2016). Hughes recently added a series on religions in global history and has a growing list of HipHughes Quickies, which distill events and historical figures into one-minute video overviews. In all, this OVR is a complete package - complemented with an active discussion board, a tech toolbox, and an extensive list of teacher tips - all of which should well serve instructors looking for assistance in introductory-level college courses. Hughes received YouTube's Next EDU Guru Award in 2012 and has appeared on the History Channel's United Stuff of America.

Although we classify the Big History Project (bighistoryproject.com/home, 2014) as a history OVR, it aspires to interdisciplinarity, ambitiously seeking to unpack " 13.8 billion years of history" by using findings from diverse physical and social sciences to explain everything from the big bang to the present in a six-hour course. The website was developed by Macquarie University history professor David Christian (see his TED talk overviewing the inception of the project, Christian, 2011) and funded largely by Bill Gates (Sorkin, 2014). Topics organized as chapters are "The Universe," "Our Solar System \& Earth, Life, Humans," and "The Modern Revolution and the Future"; video collections in the latter three chapters are especially relevant for anthropology and sociology as well as conventional history instruction. Initially intended for high school students, the site likewise has become integrated into a successful Coursera MOOC. Partnerships for creating media curriculum materials have added to the value of the project, including those with Christian's International Big History Association, Khan Academy Big History Project (with extensive applications), the YouTube site Big History, and the Crash Course series of Big History videos produced by the Green brothers for the project. The site received MERLOT's 2014 Classic Award for History. Much of the material provided at the Big History Project has been integrated into Christian's book Origin Story (2018). We should also note that among history OVR developers mentioned in this paper, Christian is the only one who actually teaches at the college level.

YouTube hosts many historically related sites, but we could not find any that distribute offerings that could be used in courses across the discipline. It's History (youtube.com/user/BlastfromthePast, 2015-present, $N>110$ ), developed by Florian Wittig and Daniel Czepelczauer, German digital media consultants, is perhaps the most promising for use in survey history courses. Working with MediaKraft Networks, they have produced a large collection of talking-head, photo-story-type videos, primarily centered on histories of military actions, the Industrial Revolution, the Cold War, and sexual behavior (e.g., "The Dark Ages of Sex: All Pleasure is Sin," Kiddey \& Czepelczauer, 2015).

Several other original-content sites with unorthodox yet imaginative takes on historical events may also pique student interest. Cody Franklin's AlternateHistoryHub (2012-present, $N>$ 150) distributes animated shorts to address such questions as "What If the United States Lost the Revolution?" (Franklin, 2014) and is one of the most popular alternative history sites, with well over one million subscribers. Two others apply music to history. Historyteachers (2008-2014, $N$ = 58), developed by Hawaii high school teachers Amy Burvall and Herb Mahelona, weds 
historically relevant lyrics to popular rock tunes sung by Amy in period costume (e.g., "French Revolution," set to Lady GaGa's "Bad Romance," Burvall \& Mahelona, 2010). Epic Rap Battles of History (2006-present, $N>65$ ) is a slick collection developed by Peter Shukoff and Lloyd Ahlquist. The site, which has won numerous awards over the past few years, pairs famous figures in edgy rap contests and allows viewers to vote for winners. Its YouTube channel, ERB, as of January 2019 had over 14 million subscribers (videos should be previewed before using in light of strong language; e.g., Shukoff \& Ahlquist, 2013). Finally, instructors who discuss blockbuster films on historical themes in class should find use for Cynical Cypher's The Cynical Historian (2013-present, $N>145$ ) and Rick Hodges' History Buffs (2015-present, $N>55$ ). Although neither was apparently developed for instructional purposes, both make for informative viewing by examining the historical accuracy of popular movies.

Despite the plethora of archival films now online (e.g., British Pathé and Internet Archive), only one OVR built around found video could be located. Have Fun with History (havefunwithhistory.com/index.html, 2009-present), developed by Maryland graphic designer Chris Grahl, provides a large collection of clips from news stories, documentaries, and popular films, with brief descriptions of content to assist U.S. history teachers. The site seems geared to younger students, but college instructors would likely find use for some (among those in the Cold War section, see "Duck and Cover," Grahl, n.d.).

Sociology. Considering social-science OVRs employing found video, one in particular, The Sociological Cinema (TSC), stands out in terms of content diversity, quality of teaching applications, and clip volume (thesociologicalcinema.com/, 2010-present, $N>600$ ). Developers Lester Andrist (University of Maryland), Valerie Chepp (Hamline University), and Paul Dean (Ohio Wesleyan University) were $\mathrm{PhD}$ candidates at the University of Maryland when they started TSC in 2010 after concluding that a website of clips tagged by theme would be invaluable to instructors interested in finding video for course use. Clips are derived from news stories, documentaries, movies, television programs and commercials, webisodes, and music videos relevant to concepts and issues. Every post includes a link to a clip, a clip summary, and a pedagogical application (e.g., "Youth Scrutinize the Hidden Curriculum, Why Don't Adults?" Grier \& Chepp, 2016). Additional materials include blog posts about popular media (e.g., "The Civilizing Habitus of the Walking Dead," Andrist, 2016), assignment outlines for media analysis, Pinterest pages for images, user discussions on the site's highly active Facebook page, and scholarly research on employing the site to foster professor-student research collaboration (see Chepp, 2017). TSC also provides instructions for posting to encourage submissions from instructors and students. The site has been favorably reviewed in Teaching Sociology (see Caldiera \& Ferrante, 2012) and received the MERLOT Classic Award for Sociology in 2012. Nevertheless, we should note that the rate of video curation at the site has significantly slowed of late, reflecting time constraints imposed by the priorities of full-time academic employment (personal communications with Andrist and Chepp, February 19, 2017).

Relevant found video is also available at several other sites. Jessie Daniels (Hunter College and CUNY) provides links to online documentaries categorized by subfield at her wiki Sociology Through Documentary Film (2009-present). Although not all of the films listed at this site are free, many titles are accompanied by "video worksheets," which link documentaries to assigned readings. DJ Academe (2012-present) developed by Laurie Chancey, sociology instructor at Asnuntuck Community College, tags every video clip by key terms but does not include teaching applications. Modestly noting at her YouTube site that she is an instructor "who collects videos to 
use in class," the collection is nonetheless extensive (e.g., about 60 videos apply just to "research ethics"). Finally, those who have struggled to convey modern theory to students should find entertaining help through Critical-Theory (2013-2015) a blog developed by Eugene Wolters (aka Slavoj Zizek), which includes found videos relevant to Marcuse, Foucault, and Chomsky, among others (e.g., "Watch: Franz Kafka Airport Named Most Alienating” Wolters, 2014).

Two other found-video sites use art to teach sociology. SocioPoetix (2013-present, $N>$ 30) focuses on poetry as an instructional tool. Developed by San Bernardino Valley College sociology instructor Anthony Blacksher (aka Ant Black), the OVR includes spoken-word videos on varied topics. Each video is accompanied by summary, key lines, transcript, analysis, and follow-up resources (e.g., "Rekia Boyd," Olayiwola \& Blacksher, 2015). SociologySounds (20122014), developed by Jason Eastman (Coastal Carolina University) and Nathan Palmer (Georgia Southern University), employed found music video, but it is no longer online (see Wayback Machine, 2012c). According to Eastman (2013), there is a strong case for the teaching utility of contemporary music, and they plan to revive the repository as time permits (personal communication, August 30, 2017).

Several collections of original-content video may also interest instructors. Norton Sociology (2010-present, $N>115$ ) provides interviews with sociologists and brief treatments of concepts and issues. Strange Fruit Sociology (2014-present, $N>45$ ), created by MiraCosta College professor Bruce Hoskins in collaboration with Ant Black (aka Anthony Blacksher), addresses current events and popular culture from a sociological perspective through mostly relaxed, humorous conversations between the two (see "Deviant White Characters on TV," Hoskins \& Black, 2015). An animated cartoon series, Sociology Live! (2015, $N=11)$, initiated by Cindy Hager, with support through her Minnesota community college employer, suggests the promise of addressing basic concepts through brief explainer videos (e.g., "White Privilege!" Hager, 2015). Finally, instructors interested in affective learning development should consider FUTURESTATES, an ITVS series consisting of short dystopian documentaries that project possible futures in light of present issues with health care, immigration, technology, and the like. The original site, which includes interactives and learning applications for early videos, can be accessed through the Wayback Machine (2013), and all five seasons $(2010-2014, N=42)$ are available on its YouTube companion. The series has been favorably reviewed by MERLOT.

Anthropology. Anthropology has two major OVRs: The Archaeology Channel and Archaeosoup. The former (archaeologychannel.org/, 2000-present, $N>110$ ), the oldest disciplinerelated OVR we could locate, was created by Richard Pettigrew under the auspices of the Archaeological Legacy Institute. The site provides both original and found content, ranging from short clips to full-length documentaries on archaeology and social anthropology subjects. Brief video summaries are included, as well as links to resource materials for further reference. The site invites interaction with content creators via email and Facebook, and solicits suggestions regarding future programs. A recent addition, "Strata: Portraits of Humanity," is a monthly series of short videos about diverse topics (e.g., the November 2017 episode featured an original documentary on Villanovan culture; Archaeological Legacy Institute, 2017). Pettigrew's work, supported by visitor-members, government agencies, and corporate donors, received the 2006 Excellence in Public Education Award from the Society for American Archaeology.

At Archaeosoup (archaeosoup.com/, 2010-present, $N>680$ ), developer Marc BarkmanAstles offers original-content talking-head narratives, interviews, and photo-story videos appropriate to high school and introductory-level college students, while also promoting 
workshops in UK schools. This OVR should spark interest in the discipline by offering informative esoterica (e.g., how ancient recipes can be cooked today, in "Ancient Greece: Honey-Glazed Prawns," Barkman-Astles, 2012b), but it also includes more complex treatments (e.g., "Cognitive Archaeology," Barkman-Astles, 2012a).

In addition, three other sites may prove helpful for teaching anthropology. The Global Oneness Project (globalonenessproject.org/, 2006-present, $N>270$ ), founded by Emmanuel Vaughan-Lee and supported by the Kalliopeia Foundation, has a growing list of original-content videos and lesson applications primarily related to cultural anthropology. One of the site's most compelling series, Vanishing Cultures, examines threatened indigenous societies around the world through video and photo essays (see "Marie's Dictionary," Vaughn-Lee, 2014). Alan Macfarlane, a retired Cambridge University professor, has curated a massive volume of film clips over his career, much of which is available at his personal website and his YouTube channel, Ayabaya (2006-present, $N>1,200$ ). These collections highlight lectures and talks he has given, and provide over 220 interviews conducted with anthropologists and other scholars (for description about creating this archive, see Macfarlane, Harrison, \& Turin, 2005). Also relevant to social anthropology is Houston Community College instructor Carol Laman's Free Online Anthropology Video (2009-2010, $N>100$ ), housed on Rice University's open-access platform Open Stax CNX. It includes self-produced lectures and found videos relevant to discipline concepts, although without summaries or learning applications.

Political science. Despite the great number of websites providing videos on political news stories, political science has the least OVR visibility. In fact, the dearth of video collections in political science has been recognized as a shortcoming by discipline leaders. A recent American Political Science Association Task Force report on the field's public image, for example, calls for an association-created video library that would "either speak directly to improving teaching effectiveness or include actual materials prepared for classroom use" (Lupia \& Aldrich, 2015, p. 5). In terms of open-access resources, nonetheless, political science today appears to be limited to addressing questions about the instructional efficacy of free textbooks (e.g., Brandle, 2018).

We could locate only one website dedicated to the discipline as a whole: Satirical Resource Repository (rebeccaglazier.net/satirical-resource-repository, 2009-2015, $N>60$ ) created by Rebecca Glazier, a University of Arkansas at Little Rock professor. The site consists of links to assorted text, image, and videos related to political science subfields (e.g., comparative politics and political theory), organized by media type, concept, and so on. Clips are largely pulled from standard political humor sources, such as The Daily Show and The Onion. While Glazier only includes a brief summary for each video, her scholarly article about using satirical content in the classroom is a major contribution to the teaching with media literature (see Glazier, 2014).

Instructors who wish to employ free media in their courses can derive materials from more limited sites within the discipline, such as The Living Room Candidate and We the Voters, a set of 20 videos with extensive ancillaries created by Paul G. Allen's Vulcan Productions and distributed by PBS for the 2016 election season. Content could also be borrowed from previously cited collections in other disciplines, such as the HipHughes History playlist of 125 videos under the U.S. Government and Politics rubric, and from several multidiscipline OVRs to be discussed in the next section. Instructors could likewise employ politically relevant content intended for general audiences (such as explainer videos relevant to political science acquired from Ezra Klein's Vox website). For those interested in creating political science OVRs, they might draw inspiration for developing content from these resources, from OVRs in other social-science disciplines, and from 
political science media accessible with textbook adoption (for a nonrepresentative sample, see “Too Late to Apologize," Soomo Publishing, 2010).

Multidiscipline sites. Although numerous sites provide video collections cutting across two or more social-science fields, several original-content sites stand out above all others. Instructors in the United States should first consider the oldest and largest trove of original documentary films - those available through PBS. ${ }^{4}$ Major series were generally initiated before the Internet, but PBS has made progressively greater amounts of content available to users at no cost since the early 2000s. Program websites typically link streaming access to films and documentaries, and often provide transcripts, clips, and associated learning materials. Several series, all produced by PBS-affiliate WGBH (Boston), seem most relevant to instructors in the social sciences. Although primarily directed to the physical sciences, NOVA (pbs.org/wgbh/nova/) includes extensive media for varied anthropology topics (see examples about evolution, WGBH, n.d.). Instructors in other social-science fields will find a rich lode in Frontline (pbs.org/wgbh/frontline/, $N>180$ ), an investigative reporting series focusing on timely social and political issues. History and political science instructors can also secure solid content at American Experience (pbs.org/wgbh/americanexperience/films/), which offers documentaries and clips on themes commonly covered in discipline curriculum (although access to some is now behind a paywall). Finally, the role played by PBS member stations in advancing media integration is important. For example, KQED (San Francisco), like WGBH, produces excellent original videos but also maintains ongoing efforts to make these resources teachable through lesson guides (see KQED Learn).

Hank and John Green's Crash Course (thecrashcourse.com/, 2011-present) likewise is an exceptional original-content repository. The Greens have had a strong YouTube presence almost from the inception of the platform, beginning with vlogbrothers in 2006 and extending to Crash Course, currently with almost 9 million subscribers. Social-science treatments at Crash Course began in 2012 with World History $(2012-2014, N=42)$, and were then successively amended by playlists on U.S. History (2013-2017, $N=48)$, Psychology (2014-2015; $N=40)$, World History 2 (2014-2017, $N=30)$, Big History (2014-2017, $N=16)$, Economics (2015-2016, $N=35)$, U.S. Government and Politics (2015-2016, $N=50)$, and Sociology (2017-2018, $N=45)$. Crash Course videos can be viewed individually or together in a holistic course. In all, they are fast-paced talking-head mini-lectures laced with campy humor, photos, and graphics, accompanied by short descriptions, often written in a similarly casual vein. New uploads can garner thousands of views within a few hours. Interest in Crash Course has expanded to include a partnership with PBS Digital Studios, the marketing of Crash Course merchandise, and the Greens' efforts to supplement YouTube advertising revenues for themselves and other creators through the subscription service, Subbable, later acquired by crowdfund vehicle Patreon.

Also at the top of original-content sites are TED and its offshoot, TED-Ed. The popular TED project (ted.com/, 2006-present, $N>2,900$ ), curated by former magazine publisher Chris Anderson, provides a massive load of filmed conference speeches delivered by scientists, writers, entrepreneurs, entertainment celebrities, and so on. Instructors should have no trouble finding relevant media for students to view outside of class. However, the concise materials offered

\footnotetext{
${ }^{4} \mathrm{BBC}$ predates PBS in providing rich content appropriate for instructional purposes. However, such programming (e.g., Horizon) is restricted to only those with a UK IP address, just as PBS resources are available only to those within the United States.
} 
through TED-Ed (ed.ted.com/, 2011-present, $N>1,000$ ) are even better for teaching and learning, in our opinion. Its objectives are ambitious, seeking to globally inspire, educate, and empower students through engaging videos and learning applications. The project provides opportunities for videos to be flipped - edited from portions of original TED presentations and other found clips. However, much of the collection consists of original animated videos, so-called TED-Ed Originals, conceptually inspired by content experts, instructors, and students that are in turn professionally animated. Each lesson forms a coherent learning package by the inclusion of multiple applications for key ideas and additional resources to consult (relevant to economics, see the explainer video "The Paradox of Value," Argawal, 2016; psychology and sociology, see "Should You Trust Unanimous Decisions?" Abbott, 2016; for history, see "The Atlantic Slave Trade: What Too Few Textbooks Ever Told You," Hazard, 2016). TED-Ed is largely funded by publisher Chris Anderson's Sapling Foundation.

Retro Report (retroreport.org/, 2013-present, $N>175$ ), an independent nonprofit news organization, also provides quality videos relevant to most of the social sciences. The series concept, developed by television editor Christopher Buck, is simple: Take a significant news story from the past and then revisit it in light of interim developments. Thus, Roane and Weiser (2015) recount the furor generated in the early 1970s with the publication of Paul Ehrlich's Population Bomb, and then they examine evidence from subsequent years, finding that not only did the destructive scenarios fail to materialize but also that population decline actually became problematical in affluent nations. Each video constitutes a succinct case study in social change and is accompanied by a summary and related references and multimedia. The website has received significant public recognition, including the 2018 Webby for Best News and Politics Series, the Gerald Loeb Award, and numerous Murrow Awards from the RTDNA.

Gapminder (gapminder.org/, 2007-present, $N>50$ ), developed by the late Hans Rosling, provides a rich collection on global development that has broad relevance for teaching across disciplines. Dedicated to curing mass ignorance with empirical evidence, Rosling employed an interactive data visualization program in his videos to draw international comparisons of life quality over historical time through real-time analysis of demographic, economic, and health variables (e.g., "Let My Data Set Change Your Mindset," Rosling, 2009). The site likewise provides numerous free downloads of teaching materials, including the analysis software and data sets. Rosling generated significant public acclaim through his Gapminder work, and the website has received substantial support through individual donors and the Swedish International Development Cooperation Agency.

Big questions addressed in brief videos are the focus of several UK multidiscipline original-content sites. These include The RSA (youtube.com/user/theRSAorg/featured) and its whiteboard-writing animated series, RSA Animate (RSA, 2010-present), with narration excerpted from speeches given to organization members (e.g., "Changing Education Paradigms," Robinson, 2010), and RSA Shorts (RSA, 2012-present), a more recent series in which cartoon animations illustrate talks about complex concepts (e.g., "Brené Brown on Blame," RSA, 2015). OpenLearn (open.edu/openlearn/, 2008-present), also provides a collection of short but engaging animated introductions, including "60 Second Adventures in Economics" (iTunes U Team, 2012) and "60 Second Adventures in Religion” (iTunes U Team, 2012); likewise see Open University's collaboration with BBC Radio4, A History of Ideas (2014-2015, $N=48)$. Instructors with a humanist bent should be sure to examine the rapidly expanding collection at The School of Life (theschooloflife.com/, 2014-present, $N>500$ ) created by philosopher Alain de Botton and art 
curator Sophie Howarth. Key to this site is The Book of Life, offering instruction on presumably how one can derive "emotional intelligence" in an increasingly materialist, competitive world. The Book includes "The Curriculum" providing text, image, and video on topics such as capitalism, work, and relationships. Various philosophers, theorists, literary figures, and the like are also explored here (e.g., "Karl Marx," The School of Life, n.d.). Access to content is facilitated through its The School of Life YouTube channel (over 4 million subscribers). Finally, Macat Analysis Videos (2015-present, $N>130$ ), developed by Salah Khalil, provides 3- to 4-minute animated book synopses categorized by social-science discipline (e.g., "An Introduction to Gordon Allport's 'The Nature of Prejudice' - A Macat Psychology Analysis," Macat, 2015).

In contrast to the above-mentioned OVRs, which generally attempt to broaden student thinking, PragerU (prageru.com/, 2013-present, $N>300$ ), developed by California radio talk-show host Dennis Prager, offers nonaccredited "courses" consisting of brief original-content videos presenting arguments for nationalist, free market, and anti-environmentalist views. PragerU's stated purpose is "to influence culture through digital content that advances Americanism" (PragerU, n.d.-b). Moreover, PragerU attempts to actively oppose left-leaning forces in higher education perceived as being dominant and threatening by offering teaching materials and a student-activist vehicle (PragerU, n.d.-a). Its YouTube companion site identifies over 100 videos for Political Science, more than 50 for Economics, and over 40 for History. Race Relations, consisting of seven videos, is treated as a course in itself (see "Are the Police Racist?" PragerU, 2016). The site uses a range of personalities to narrate videos, including mainstream conservatives like George Will, as well as younger speakers, such as Adam Corolla and Ben Shapiro, who appear to especially resonate with the young subscribers the site is trying to reach (Oppenheimer, 2018). The website solicits private donations and also is generously supported by Texas petroleum fracking industry billionaires Dan and Farris Wilks (Shea, 2015). Its YouTube channel presently has about 2 million regular viewers, although YouTube has placed 28 of its videos on restricted access since fall 2016 (Roberts, 2016).

Finally, developers working alone to produce well-crafted interdisciplinary content should be recognized. C.G.P. Grey, Evan Puschak, and Jonathon McIntosh are three of the best in our opinion. Grey distributes his videos with social-science themes at CGP Grey (2010-present, $N>$ 115, see "The Rules for Rulers," Grey, 2016) and has also built a scaffold for learning through ongoing discussion with followers on his blog and at Reddit). Puschak, aka The Nerdwriter (2011present, $N>115$ ) works to "cultivate worldview" by producing 5- to 10-minute video essays across diverse topics, including a growing number relating to social behavior (see "Essays about the Social Sciences," Puschak, 2012-2016). Puschak publishes three or four videos monthly, for which he is crowdfunded through Patreon. McIntosh employs critical social analysis through his Popular Culture Detective Agency blog (2016-present). Each video is accompanied by a synopsis, links to sources, recommended readings, and full transcript (e.g., "Military Recruitment and Science Fiction Movies," McIntosh, 2016). McIntosh has been active over the past decade in examining the intersection of media, gender, and subversive video, and his YouTube site provides easy access to current and previous works. He likewise seeks crowdfunded support through Patreon.

In contrast to original-content websites, found-content OVRs have had far less success, typically experiencing slow or no growth. The Open Video Project (open-video.org/) was initiated in 1998 at the Interaction Design Lab, University of North Carolina, Chapel Hill "to collect and make available a repository of digitized video content for the digital video, multimedia retrieval, 
digital library, and other research communities" (Open Video Project, n.d.). The project apparently has more relevance for conducting technical research on video storage and distribution than building a viable collection: Most were added in the early 2000s, many of those with social-science relevance are from the Internet Archive, and all are in the form of downloadable files. HippoCampus.org (hippocampus.org/, 2003) bills itself as "a free, core academic web site that delivers rich multimedia content-videos, animations, and simulations - on general education subjects to middle-school and high-school teachers and college professors, and their students, free of charge." Sponsored by the Monterey Institute for Technology, it has received substantial support through the Gates and Hewlett foundations. Videos for economics, government, history, and sociology are available, but curated collections have grown little since the inception of the site. Moreover, they tend to be derived from only a limited set of primary collections (e.g., all 15 sociology clips were culled from one Dallas Learning Solutions film).

In fact, found-content multidiscipline sites have often not survived. Mindgate Media (2008-2012), arguably the best multidiscipline OVR employing found video, is no longer online (see Wayback Machine, 2012a). Created by Lisa Lewin, former textbook publishing executive, the website offered creative and technical services to those wishing to integrate video into products, but the core was its on-demand feature, showcasing an impressive collection of found clips and lesson applications across the entire curriculum (see Wayback Machine, 2012b). Content, largely contributed by college instructors, included summaries, class-usage suggestions, related readings, comments, and user ratings. However, the website, intended to be for-profit, closed in 2012 as its on-demand service never could be monetized. The UK's premier found-video content site, government-supported JISC Digital Media (2009-2016) also closed as part of a larger reorganization effort (see archived version at UK Web Archive). The original site provided over 300 found-video clips with brief summaries relevant to social-science disciplines, but the collection is now available only behind a paywall at Alexander Street. Likewise, Resourcd, a UK crowd-sourced site offering found clips across multiple disciplines since 2007, appeared to go offline last year (see Wayback Machine, 2019).

Conversely, Critical Commons (criticalcommons.org/, 2009-present), housed at the University of Southern California and developed by Steve Anderson, media professor now at UCLA, is a massive found-content site that continues to grow. This OVR, which has received ongoing support from the MacArthur and the Mellon foundations, as well as the NEH, was initiated as an online space for establishing fair use for scholars who employ copyrighted content in transformative works. Included with each embedded clip is commentary making it relevant to teaching and learning, and necessary to meet the fair use standard and distribution on the site (e.g., "Disrupting Sexism in the Workplace," Sarkeesian, n.d.). The site includes individual collections and serves as a storehouse for edited clips in turn employed in other OVRs. Its holdings are vast $(N>7,500)$ and have been augmented particularly through contributions from economics instructors, who have submitted more than 1,000 clips (see Critical Commons, 2019).

\section{Discussion}

Subsequent to our review of social-science OVRs, four generalizations seem relevant: (1) recent emergence and sustained development, (2) extensive differences in forms and features, (3) major cross-disciplinary distinctions, and (4) varied motives and support. Findings also imply suggestions about possible directions for future OVR development. 
Recent emergence and sustained development. Consistent with the explosion of online video in general, OVRs have emerged only recently in significant numbers, a function to some extent of technological innovations that made streaming an efficient mode of transmission. Of the more than 70 repositories described in this paper, just one (Online Video Project) started before 2000; virtually all others were created in the past 15 years. Importantly, most have continued to augment content since inception. Well over 50 repositories distributed video on relevant platforms through 2018. We could determine that only several had gone offline altogether. The emergence of many over the last several years indicates that interest in OVR development remains strong and that few older sites appear to be slowing down in terms of video curation.

Differences in forms and features. As shown, OVRs range markedly in terms of complexity, design sophistication, video type, video production values, collection size, and learning applications. Some have diverse functional features with massive amounts of curated video and ancillaries. Conversely, a few are little more than PDFs with links to videos and limited or no commentary.

One important difference lies in source of video content. Overall, about three times as many OVRs employ original content in comparison to found content. Edited-content sites are virtually nonexistent outside economics. As suggested, applications can be important, particularly with found and edited content. Most provide tags and/or clip summaries at the very least, but some also go well beyond by providing practical information about integrating videos with teaching.

In addition to categorizing videos by topic or tags, several other features are common across OVRs. Almost all make use of social media, enabling users to communicate about site content. Most encourage users to give specific comments about clips. User involvement is particularly critical for sites that rely on found video, and some give instructions to encourage quality user input. An active Facebook presence also can generate significant user interaction that might not transpire otherwise. Many original-content OVRs have a YouTube companion, which can facilitate interaction, as well as enhance visibility, user access, and advertising revenue.

Major cross-disciplinary distinctions. OVR development has been markedly uneven across disciplines. As shown, economics and psychology have over 30 between them; at the other end, political science has one.

Economics websites make significant use of popular culture. Many are populated by professionally produced content, with several employing well-developed satirical storylines and skilled performers. Economics likewise has numerous sites dedicated to given ideological perspectives, including Learn Liberty, a site whose developers are single-mindedly fixed on aiming provocative content at particular students and recruiting them into organization programs. Economics also is unique in having all but one of the many edited-content sites.

Psychology is exceptional in terms of website diversity. Many of its OVRs are professor made, while other sites encourage students to interview professors. Psychology is the only discipline in which some developers choose to withhold their identities, is the only discipline for which a book publisher provides a collection of found clips, and has the only one created and maintained by undergraduates.

Other disciplines are notew orthy for more limited reasons. History has the most extensive collection developed by a single instructor (HipHughes), the only site which tries to explain everything (Big History Project), and several which employ entertaining vehicles to reach students. 
Sociology has the exemplar in found video, The Sociological Cinema, a huge OVR built around crowdsourced materials. Anthropology has the oldest discipline-focused site (The Archaeology Channel). And political science is remarkable for its lack of OVR development.

Multidiscipline OVRs consisting of original materials are plentiful and have a rapidly expanding base of content (witness the rapid growth of Crash Course, TED-Ed, The School of Life, and PragerU). Such sites are by nature large projects that require substantial funding and relate to broad subject matter across the social sciences. In contrast, multidiscipline sites using found content generally have not fared well. With the exception of Critical Commons, they have been less productive and shorter lived than original-content repositories.

Varied motives and support. The OVR environment is diverse relative to developer motives and funding. Some OVRs have been driven by interests outside academia, although few were apparently initiated to become for-profit sites. Many economics websites were created for the clear purpose of promoting ideological perspectives, but most discipline-specific sites were developed by high school and college instructors seemingly committed to nothing more than the advancement of teaching and learning.

OVR financial support likewise significantly varies. Some appear to be exceptionally well funded, particularly those receiving contributions from wealthy donors with political agendas. Some instructors have received or continue to get financial or service assistance from college employers, but many others appear to be without institutional support. For such developers, crowdfunding and YouTube advertising revenue have become prominent. Moreover, many OVRs were developed by instructors who seem neither motivated by money nor in need of large amounts of it to do their online work. They thus represent an important counterforce to what has been termed "the marketization of higher education" (Palmer \& Schueths, 2013). Consequently, favorable recognition from employers for capably doing so - and perhaps the greater discipline - might go a long way in encouraging others to become involved in OVR development.

Future research. Most immediately relevant to us are questions emerging from our findings, such as why OVRs diverge so widely across disciplines and why original-content sites are far more common than those employing found or edited video. OVR quality should also be addressed. Do extant videos and applications meet essential pedagogical standards? MERLOT provides guidance for determining content and website adequacy and, as shown, has already reviewed some of the OVRs considered here. However, evaluation efforts should be extended to include all major websites, especially those appearing to be ideologically driven. Research might also be directed to OVR employment, as we are not aware of the extent to which they are integrated in practice into teaching. Such research should also seek to identify obstacles to use. Finally, we encourage research about OVRs in other fields. Examination of those in the physical and life sciences, math, business, and the humanities would be helpful for bringing resources to the surface for broader instructional use and assessment, as well as for understanding the larger OVR universe specific to higher education.

\section{Acknowledgements}

We appreciate the generous editing assistance of Barbara Millis, the critical feedback of numerous OVR developers to an earlier draft, and the helpful suggestions of OLJ reviewers. 


\section{References}

Abbott, D. (2016, March). Should you trust unanimous decisions? - Derek Abbott [Video file]. Retrieved from https://ed.ted.com/lessons/should-you-trust-unanimous-decisions-derekabbott

Al-Bahrani, A., Libis, B., Drabik, S., \& Gibson, J. (2017) Econ Beats: A semester long, interdisciplinary, project-based learning assignment. Journal of Economics and Finance Education, 16(3) 1-10. Retrieved from https://papers.ssrn.com/sol3/papers.cfm?abstract_id=3093382

Allen, P., \& Spurlock, M. (2014a). About. Retrieved from https://wetheeconomy.com/about/

Allen, P., \& Spurlock, M. (2014b). Resources. Retrieved from https://wetheeconomy.com/resources/

Alpert, F. (2016). Revitalizing the live lecture with instructor-created videos. SAGE Open, 6(4) 1-12. doi:10.1177/2158244016680686. Retrieved from http://journals.sagepub.com/doi/pdf/10.1177/2158244016680686

Andrist, L. (2016, April 10). The civilizing habitus of the Walking Dead [Blog post]. Retrieved from https://www.thesociologicalcinema.com/blog/the-civilizing-habitus-of-the-walking-dead

Andrist, L., Chepp, V., Dean, P., \& Miller, M. (2014). Toward a video pedagogy: A teaching typology with learning goals. Teaching Sociology, 42, 196-206. doi:10.1177/0092055X14524962.

Archaeological Legacy Institute. (2017, November). Strata - November 2017. Retrieved from http://www.archaeologychannel.org/video-guide/strata-portraits-of-humanity/2669-stratanovember-2017

Argawal, A. (2016, August). The paradox of value [Video file]. Retrieved from https://ed.ted.com/lessons/the-paradox-of-value-akshita-agarwal\#

Bahrani, R. (2014). Lemonade war [Video file]. Retrieved from https://wetheeconomy.com/films/lemonade-war/

Barakat, A. (2016, April 1). George Mason University becomes a favorite of Charles Koch. AP. Retrieved from https://apnews.com/613470e79eb64a5f9a4880996e0fd7c5/george-masonuniversity-becomes-favorite-charles-koch

Barkman-Astles, M. [Archaeosoup]. (2012a, January 26). Aspects of archaeology: Cognitive anthropology [Video file]. Retrieved from https://youtu.be/-H1j_shtztI

Barkman-Astles, M. [Archaeosoup]. (2012b, July 27). Ancient Greece: Honey-glazed prawns [Video file]. Retrieved from https://youtu.be/JcY-p4CNJzM

Bennett, B. (2016a). The structure of each entry. Retrieved from https://www.dowellwebtools.com/tools/lp/Bo/psyched/5/The_Structure_of_Each_Entry

Bennett, B. (2016b). Xerox mindfulness experiment. Retrieved from https://www.dowellwebtools.com/tools/lp/Bo/psyched/18/Xerox_Mindfulness_Experiment

Berk, R. (2010). How do you leverage the latest technologies, including Web 2.0 tools, in your classroom? International Journal of Technology in Teaching and Learning, 6(1), 1-13.

Bite Size Psych. (2015, May 28). Debunking the 4 most dangerous self-help myths [Video file]. Retrieved from https://youtu.be/JB3oxye8Kd8 
Brandle, S. (2018). Opening up to OERs: Electronic original sourcebook versus traditional textbook in the introduction to American government course. Journal of Political Science Education, 14, 535-554. doi:10.1080/15512169.2017.1420482.

Britt, M. (2014). Ep 224: If Freud worked tech support [Video file]. Retrieved from http://www.thepsychfiles.com/2014/08/ep-224-video-if-freud-worked-tech-support/

Britt, M. (2017). Ep 296: The psychology and the research behind why some people are angry when athletes take a knee [Audio file]. Retrieved from http://www.thepsychfiles.com/2017/11/ep296-psychology-research-behind-people-angry-athletes-take-knee/

Brugger, N. (2009). Website history and the website as an object of study. New Media and Society, 11(1-2), 115-132. doi:10.1177/1461444808099574

Burvall, A., \& Mahelona, H. [Historyteachers]. (2010, September 14). French Revolution [Video file]. Retrieved from https://youtu.be/wXsZbkt0yqo

Caldeira, C., \& Ferrante, J. (2012). The Sociological Cinema: Teaching and learning sociology through video. Teaching Sociology, 40, 191-193. doi:10.1177/0092055X12439856

Cengage. (2016, June 6). Dealing with the office bully. Retrieved from http://clipsforclass.com/dealing-with-the-office-bully.html

Chepp, V. (2017). Equity-minded high-impact learning: A short-term approach to student-faculty collaborative research. Humboldt Journal of Social Relations, 39, 163-175. Retrieved from http://digitalcommons.humboldt.edu/hjsr/vol1/iss39/17/

Christian, D. (2011). The history of our world in 18 minutes [Video file]. Retrieved from https://www.ted.com/talks/david_christian_big_history?language=en

Christian, D. (2018). Origin story: A big history of everything. Little, Brown: New York.

Clifford, J. [ACDCLeadership]. (2015, November 9). Capitalism and The Hunger Games: Econmovies \#10 [Video file]. Retrieved from https://youtu.be/tzXzkAs_cf0

Clifford, J. [ACDCLeadership]. (2017, February 3). The economics of Trump with Jacob Clifford, part 1-trade. [Video file]. Retrieved from https://youtu.be/_GrjO-oRQ5M

Coiffe, D. (2014). Harnessing open Internet media resources. Proceedings of the IATUL Conferences (Paper 3). Retrieved from http://docs.lib.purdue.edu/iatul/2014/dlspace/3

Critical Commons. (2019). Search results for economics. [Search list]. Retrieved from http://www.criticalcommons.org/@ @ search?SearchableText=economics\&portal_type=Plumi Video

Daniels, J. (2012). Transforming student engagement through documentary and critical media literacy. Theory in Action, 5(2), 5-29. doi:10.3798/tia.1937-0237.12011

Eastman, J. (2013, January 8). Teaching sociology with music videos [Blog post]. Retrieved from http://www.thesociologicalcinema.com/blog/teaching-sociology-with-music-videos

Ferrarini, T., \& Mateer, G. (2014). Multimedia technology for the next generation. Journal of Private Enterprise, 29(2), 129-139. Retrieved from

http://journal.apee.org/index.php?title=2014.Spring.JPE_part8.pdf

Foundation for Economic Education. (2017, February 1). A new FEE for the $21^{\text {st }}$ century [Video file]. Retrieved from https://youtu.be/1yFHI1n7Xow 
Foundation for Economic Education. (2018, December, 6). The anti-authoritarian politics of Harry Potter [Video file]. Retrieved from https://youtu.be/g4TEtalsISY

Franklin, C. [AlternativeHistoryHub]. (2014, February 14). What if the United States lost the revolution? [Video file]. Retrieved from https://youtu.be/6RN8kft-2wo

Ghent, L., Grant, A., \& Lesica, G. (2010). The baby shower [Video file]. Retrieved from http://yadayadayadaecon.com/clip/7/

Ghent, L., Mateer, G., \& Stone, M. (2010-2011). TV for economics [Blog]. Retrieved from http://tvforecon.blogspot.com/

Glazier, R. (2014). Satire and efficacy in the political science classroom. PS: Political science and politics, 47(4), 867-872. doi:10.1017/S104909651400119X

Gibson, C. (2017, January 28). To Charles Koch, professors are lobbyists. The Huffington Post. Retrieved from http://www.huffingtonpost.com/connor-gibson/to-charles-kochprofessor_b_9100904.html

Grahl, C. (n.d.). Duck and cover [Video file]. Retrieved from http://havefunwithhistory.com/movies/duckCover.html

Green, H. [SciShow Psych]. (2017, April 24). Are violent video games bad for you? [Video file]. Retrieved from https://youtu.be/qwv_wTUNwLs

Grey, C. [CGP Grey]. (2016, October 24). The rules for rulers [Video file]. Retrieved from https://youtu.be/rStL7niR7gs

Grier, J., \& Chepp, V. (2016, January 12). Youth scrutinize the hidden curriculum, why don't adults? Retrieved from https://www.thesociologicalcinema.com/videos/youth-scrutinize-the-hiddencurriculum-why-dont-adults

Hager, C. [Sociology Live]. (2015, October 15). White privilege! [Video file]. Retrieved from https://youtu.be/ZLgbw_A1mLI

Haran, B. [PsyFile]. (2013, January 15). 10 percent of your brain [Video file]. Retrieved from https://youtu.be/owWxYJ7Bu14

Hazard, A. (2016, December). The Atlantic slave trade: What too few textbooks told you. Retrieved from https://ed.ted.com/lessons/the-atlantic-slave-trade-what-your-textbook-never-told-youanthony-hazard

Hill, V. (2016). The bizarre ways your name affects your behavior [Video file]. Retrieved from http://www.pbs.org/video/braincraft-name/

HippoCampus.org. (n.d.) About. Retrieved from http://www.hippocampus.org/HippoCampus/

Holder, K. [Macmillan Learning]. (2015, January 17). Kim Holder: Rockonomix hits [Video file]. Retrieved from https://youtu.be/8y4vfmPxwTE

Hoskins, B., \& Ant Black. [Strange Fruit Sociology]. (2015, January 8). Deviant white characters in $T . V$. shows [Video file]. Retrieved from https://youtu.be/NUKfT16iQHg

Hughes, K. [HipHughes History]. (2012-2016). Presidential elections explained [YouTube playlist]. Retrieved from https://www.youtube.com/playlist?list=PL8C7B72D8B769A0A0 
Independent Institute. (2015). Love Gov: From first date to mandate [YouTube playlist]. Retrieved from https://www.youtube.com/watch?v=pSGgm8TIMFU\&list=PL8FSqhf6cNym7XLfQhYfvPH8MSgsmXW8

Independent Institute. (2017). Love Gov in the news. Retrieved from http://www.independent.org/lovegov/news.asp

iTunes U Team. (2012, September). 60 second adventures in economics [Playlist]. Retrieved from http://www.open.edu/openlearn/society/politics-policy-people/economics/60-secondadventures-economics

iTunes U Team. (2012, September). 60 second adventures in religion [Playlist]. Retrieved from http://www.open.edu/openlearn/history-the-arts/culture/religious-studies/60-secondadventures-religion

Jaszi, P., \& Aufderheide, P. (2008). Code of best practices in fair use for online video. Washington, DC: American University Center for Social Media. Retrieved from http://cmsimpact.org/wpcontent/uploads/2016/01/online_best_practices_in_fair_use.pdf

Kaufman, P. (2007). Video, education, and open content: Notes toward a new research and action agenda. First Monday, 12(4). Retrieved from http://firstmonday.org/ojs/index.php/fm/article/view/1767/1647

Kiddey, G. (Writer/Host), \& Czepelczauer, D. (Director) [It's History]. (2015, September 21). The dark ages of sex: All pleasure is sin [Video file]. Retrieved from https://youtu.be/hVD2Z7ib_nE

Kotch, A. (2017, February 2). Charles Koch ramps up higher ed funding to fuel "talent pipeline." $P R$ Watch. Retrieved from http://www.prwatch.org/news/2017/01/13210/charles-koch-rampshigher-ed-funding-talent-pipeline

Kuester, D., \& Youderian, C. (2013). Write that down. Retrieved from http://economicsoftheoffice.com/all/?id=2

Learn Liberty. (2013). Is Katniss a modern day Spartacus? Retrieved from http://www.learnliberty.org/videos/katniss-modern-day-spartacus/

Learn Liberty. (2014a). Frank Underwood's top 3 lessons for the voting public: House of Cards review. Retrieved from http://www.learnliberty.org/videos/frank-underwoods-top-3-lessons/

Learn Liberty. (2014b). Sexonomics: The economics of love and dating. Retrieved from http://www.learnliberty.org/course_details/the-economics-of-love-and-dating-on-demand/

Learn Liberty. (2015a). I can’t breathe: How to reduce police brutality. Retrieved from http://www.learnliberty.org/videos/3496/

Learn Liberty. (2015b). Should you be allowed to sell your kidneys? Retrieved from http://www.learnliberty.org/videos/should-you-be-allowed-to-sell-your-kidneys/

Learn Liberty. (2016). Economics: Is raising minimum wage a bad idea? Retrieved from http://www.learnliberty.org/videos/raising-minimum-wage-bad-idea/

Lee, J. (2016, March 29). 10 seconds at a time, a teacher tries Snapchat to engage students. NPR. Retrieved from https://www.npr.org/sections/ed/2016/03/29/467091289/how-teachers-areusing-snapchat 
Leet, D., \& Houser, S. (2003). Economics goes to Hollywood: Using classic films to create an undergraduate economics course. Journal of Economic Education, 34(4), 326-332.

Lupia, A., \& Aldrich, J. (2015). How political science can better communicate its value: 12 recommendations from the APSA Task Force. PS: Political Science and Politics, 34(S1), 1-19. doi-org.libweb.lib.utsa.edu/10.1017/S1049096515000335

Luttrell, A. (2016, February 2). A crash course on cognitive dissonance. Retrieved from http://socialpsychonline.com/2016/02/cognitive-dissonance/

Macat. (2015). An introduction to Gordon Allport's The Nature of Prejudice-A Macat Psychology Analysis [Video file]. Retrieved from https://youtu.be/9mGxJkFVQpI

Macfarlane, A., Harrison, S., \& Turin, E. (2005). Anthropological and other ancestors: Notes on setting up a visual archive of the discipline. Anthropology News, 46, 21-22.

doi:10.1525/an.2005.46.9.21

Marshall, C. (2014, September 18). A crash course on psychology: A 30 part video series from Hank Green. Open Culture. Retrieved from http://www.openculture.com/2014/09/a-crash-courseon-psychology.html

Mateer, G. (n.d.). Gangs of New York - ending. Retrieved from http://dirkmateer.com/media/Film+Clips/gangs-of-new-york

Mateer, G., Ghent, L., Porter, T., \& Purdom, R. (2014). Using media to enhance teaching and learning. SERC, Starting Point: Teaching and Learning Economics. Retrieved from https://serc.carleton.edu/econ/media/index.html

Mateer, G., O'Roark, B., \& Holder, K. (2016). The 10 greatest films for teaching economics. The American Economist, 61(2), 204-216. doi:10.1177/0569434516653749

Mateer, G., \& Stephenson, E. (2011). Using film clips to teach public choice economics. Journal of Economics and Finance Education, 10(1), 28-36. Retrieved from http://cafehayek.com/wpcontent/uploads/2011/07/Dirk-Mateer-and-Frank-Stephenson-explain-how-to-use-film-clipsto-better-convey-to-students-the-lessons-of-public-choice-economics..pdf

Mayer, J. (2016). Dark money: The hidden history of the billionaires behind the rise of the radical right. Random House: New York.

McIntosh, J. (2016, September 29). Military recruitment and science fiction movies [Blog post]. Retrieved from http://popculturedetective.agency/2016/military-recruitment-and-sciencefiction-movies

Melichar, M. (2017). Red, white, pink slip blues. Retrieved from http://www.econgonecountry.com/red--white--and-pink-slip-blues.html

Miller, M. (2011). A system for integrating online multimedia into college curriculum. Journal of Online Learning and Teaching, 7(2), 1-19. Retrieved from http://jolt.merlot.org/vol7no2/miller_0611.htm

New York Magazine [Science of Us]. (2016, February 25). Is casual sex unhealthy? [Video file]. Retrieved from https://youtu.be/FEq3csWqwMo

Olayiwola, P. (Poet/Performer), \& Blacksher, A. (Curator). (2015, November 2). Rekia Boyd. Retrieved from http://sociopoetix.org/analysis/rekia-boyd/ 
Open Video Project. (n.d.). Project description. Retrieved from https://openvideo.org/project_info.php

Oppenheimer, M. (2018, March/April). Inside the right-wing YouTube empire that's quietly turning millennials into conservatives. Mother Jones. Retrieved from https://www.motherjones.com/politics/2018/03/inside-right-wing-youtube-turningmillennials-conservative-prageru-video-dennis-prager/

Palmer, N., \& Schueths, A. (2013). Online teaching communities within sociology: A counter trend to the marketization of higher education. Teaching in Higher Education, 18(7), 809-820. doi:10.1080/13562517.2013.836097

Papola, J. (2014). EconPop: Dallas buyers club. Retrieved from http://econstories.tv/video/econpopdallas-buyers-club/

Papola, J., \& Roberts, R. (2010, January 23). Fear the boom and bust [Video file]. Retrieved from https://youtu.be/d0nERTFo-Sk

Papola, J., \& Roberts, R. (2011, April 23). Fight of the century [Video file]. Retrieved from https://youtu.be/GTQnarzmTOc

PragerU. (n.d.-a). Student ambassador program. Retrieved from https://www.prageru.com/studentambassador-program

PragerU. (n.d.-b). About us. Retrieved from https://www.prageru.com/about/

PragerU. (2016, August 22). Are the police racists? Retrieved from https://www.prageru.com/videos/are-police-racist

Psych2Go. (2017, February 11). 10 signs an introvert likes you [Video file]. Retrieved from https://www.youtube.com/watch?v=UPcJx_VQYBU

PsychoTube. (n.d.). Human brains compared to other animals. Retrieved from https://www.psychotube.net/physiological-psychology/human-brains-compared-to-otheranimals/

Psynfeld. (2012). Morality according to Kohlberg. Retrieved from http://psynfeld.tumblr.com/post/22445936700/morality-according-to-kohlberg

Puschak, E. [The Nerdwriter]. (2012-2016). Essays about the social sciences [YouTube playlist]. Retrieved from https://www.youtube.com/playlist?list=PLwg4AG1KkgLz2pLNCT97EbZgwCgnTV_kR

Reich, R. [Inequality Media]. (2017, October 5). The failure of trickle-down economics [Video file]. Retrieved from https://youtu.be/cABuFmA3nhY

Roane, K., \& Weiser, S. (2015, June 1). The population bomb? Retrieved from https://www.retroreport.org/video/the-population-bomb/

Roberts, J. (2016, October 21). Why critics say YouTube is censoring conservative videos. Fortune. Retrieved from http://fortune.com/2016/10/21/youtube-prageru/

Robinson, K. [RSA]. (2010, October 14). Changing education paradigms [Video file]. Retrieved from https://youtu.be/zDZFcDGpL4U

Rosling, H. (2009). Let my data set change your mindset. Retrieved from https://www.gapminder.org/videos/ted-us-state-department/ 
RSA. (2015, February 13). Brené Brown on blame [Video file]. Retrieved from https://youtu.be/RZWf2_2L2v8

Sarkeesian, A. (n.d.). Disrupting sexism in the workplace. Retrieved from http://www.criticalcommons.org/Members/femfreq/clips/fringe1x06a-emotions.mov/view

The School of Life. (n.d.). Karl Marx. The Book of Life. Retrieved from https://www.theschooloflife.com/thebookoflife/the-great-philosophers-karl-marx/

Shea, B. (2015). Fracking titans spend millions proselytizing school children. Rewire. Retrieved from https://rewire.news/article/2015/04/30/conservatives-spend-millions-proselytizing-schoolchildren/

Sherer, P., \& Shea, T. (2011). Using online video to support student learning and engagement. College Teaching, 59, 56-59. doi:10.1080/87567555.2010.511313

Shukoff, P., \& Ahlquist. L. [ERB]. (2013, February 25). Gandhi vs. Martin Luther King, Jr. [Video file]. Retrieved from https://youtu.be/-6G6CZT7h4k

Snelson, C. (2011). YouTube across the disciplines: A review of the literature. Journal of Online Learning and Teaching, 7(1), 159-169. Retrieved from http://jolt.merlot.org/vol7no1/snelson_0311.pdf

Soomo Publishing. (2010, February 2). Too late to apologize [Video file]. Retrieved from https://youtu.be/uZfRaWAtBVg

Sorkin, A. (2014, September 5). So Bill Gates has this idea for a history class... New York Times. Retrieved from https://www.nytimes.com/2014/09/07/magazine/so-bill-gates-has-this-ideafor-a-history-class.html

Stossel, J. (2017a). Eye test innovators. Retrieved from http://stosselintheclassroom.org/videos/eye_test_innovators/

Stossel, J. (2017b, July 19). Launch of Stossel TV [Video file]. Retrieved from https://youtu.be/UXaswX1ujEA

Streeter, D. (2011). Using digital stories effectively to engage students. In C. Wankel \& J. Law (Eds.), Streaming media delivery in higher education: Methods and outcomes (pp. 175-198). Hershey, PA: Information Science Reference (IGI Global).

Tierney, J., Geerling, W., Wooten, J., Mateer, D., \& Smith, B. (n.d.). Causation vs. correlation. Retrieved from http://www.bazinganomics.com/causation-vs-correlation/

UNESCO. (2018). Open educational resources. Retrieved from https://en.unesco.org/themes/building-knowledge-societies/oer

Vaughn-Lee, E. (2014). Marie's dictionary. Retrieved from https://www.globalonenessproject.org/library/films/maries-dictionary

WGBH. (n.d.) Evolution. NOVA. Retrieved from https:/www.pbs.org/wgbh/nova/topic/evolution/

Wayback Machine. (2012a, March 9). Mindgate Media. Retrieved from https://web.archive.org/web/20120309142023/http:/mindgatemedia.com/

Wayback Machine. (2012b, January 12). Mindgate Media: On-demand. Retrieved from https://web.archive.org/web/20120107041610/http:/mindgatemedia.com/ondemand/ 
Wayback Machine. (2012c, June 19). SociologySounds. Retrieved from http://web.archive.org/web/20120619032308/http:/www.sociologysource.com:80/sociologys ounds/

Wayback Machine. (2013, June 17). FUTURESTATES. Retrieved from http://web.archive.org/web/20130617164650/http://www.futurestates.tv/

Wayback Machine. (2019, November 20). Resourcd. Retrieved from http://web.archive.org/web/20181120034747/http://www.resourcd.com/

Weisberger, M. (2016, July 7). YouTube's "BrainCraft" peers at the science of the brain. Live Science. Retrieved from http://www.livescience.com/55305-youtube-braincraftneuroscience.html

Werner, S. (n.d.-a). Can synesthesia be acquired? Retrieved from http://gocognitive.net/interviews/can-synesthesia-be-acquired

Werner, S. (n.d.-b). Monsters and globes problems. Retrieved from http://gocognitive.net/demo/monsters-and-globes-problem

Wolters, E. (2014). Watch: Franz Kafka Airport named most alienating. Retrieved from http://www.critical-theory.com/watch-pragues-franz-kafka-airport-named-most-alienating/

Wooten, J. (2017a). The daily show: Ugly people discrimination. Retrieved from https://videoecon.wordpress.com/2017/11/27/the-daily-show-ugly-people-discrimination/

Young, C. (2014, August 26). Koch-funded think tank offers schools course in libertarianism. The Center for Public Integrity. Retrieved from https://www.publicintegrity.org/2014/08/26/15387/koch-funded-think-tank-offers-schoolscourse-libertarianism

Zaitchik, A. (2013, February 25). The right-wing money putting John Stossel in classrooms [Blog post]. Retrieved from https://www.mediamatters.org/blog/2013/02/25/the-right-wing-moneyputting-john-stossel-in-sc/192777 